\title{
Myeloid Proliferation Index
}

National Cancer Institute

\section{Source}

National Cancer Institute. Myeloid Proliferation Index. NCI Thesaurus. Code C135436.

The determination of the ratio of the sum of myeloid proliferative phase cells (pool) to the sum of myeloid maturation phase cells (pool) present in a sample. 